Pak. j. sci. ind. res. Ser. A: phys. sci. 2018 61A(3) 138-144

\title{
Analysis of Water in the Area of District Sahiwal for Heavy Metals (A Case Study)
}

\author{
Muhammad Zahir ${ }^{\mathrm{a}}$, Zahid Qureshi ${ }^{\mathrm{b}}$, Shahid Tufail ${ }^{\mathrm{a}}$, Khizar Hayat*cd and Ahmad Hassan ${ }^{\mathrm{a}}$ \\ ${ }^{a}$ Department of Chemistry, Minhaj University Lahore, Punjab, Pakistan \\ ${ }^{b}$ Department of Chemistry, Government College University Lahore, Punjab, Pakistan \\ ${ }^{\mathrm{c}}$ Department of Chemistry, Quaid-i-Azam University, Islamabad, Pakistan \\ ${ }^{\mathrm{d}}$ Department of Chemistry, Government P/G College of Science, Faisalabad, Punjab, Pakistan
}

(received January 26, 2018; revised July 10, 2018; accepted July 11, 2018)

\begin{abstract}
Current study was conducted to analyze the water in the area of Sahiwal district for toxic metals. This study gives information about the concentrations of three toxic metals, arsenic (As), lead $(\mathrm{Pb})$ and chromium $\mathrm{Cr}$ (III). Total of 20 samples were collected, including tap, filter plant, hand pump and tubewell water. The levels of $\mathrm{As}(\mathrm{III})$ and $\mathrm{Cr}(\mathrm{VI})$ were determined using spectrophotometer while $\mathrm{As}_{\text {total }}, \mathrm{Cr}_{\text {total }}$ and $\mathrm{Pb}$ concentrations were analysed by using inductively coupled plasma-mass spectrometry (ICP-MS). The results of chromium were above EPA recommended value $(0.05 \mathrm{ppm})$ in all the samples. On the other hand, the concentrations of arsenic and lead were lower than Pak-EPA Standard limits. The mean level of chromium was $5.559 \mathrm{mg} / \mathrm{L}$ which was 111.18 times higher than $\mathrm{WHO}$ and local standard of $0.05 \mathrm{mg} / \mathrm{L}$. Similarly, the mean level of arsenic and lead were $10.668 \mu \mathrm{g} / \mathrm{L}$ and $7.037 \mu \mathrm{g} / \mathrm{L}$, respectively, which were 4.687 and 7.1053 times, respectively lower than Pak-EPA Standard value of $50 \mu \mathrm{g} / \mathrm{L}$.
\end{abstract}

Keywords: Sahiwal area, arsenic, chromium, lead, ICP-MS, spectrophotometer

\section{Introduction}

Two basic requirements of each individual are sanitation and water supply (Ikhlaq et al., 2014). Some elements are supplied by water but when water is contaminated, it becomes the source of such substances which cause diseases in human beings. Most common diseases caused by polluted water are different kinds of cancer, teeth decay, cardiovascular, reproductive and neurological diseases. It has been observed that the rate of effects of toxic metals is greater in children than adults (Johnson and Hallberg, 2005).

Arsenic (As) and its compounds i.e., arsenicals are hazardous to human beings. Anthropogenically, they come in water from ceramic, glassware, metallurgic products, fertilizers, pesticide, petroleum and other industries. Some sources of arsenic are also natural like soil (Tareen et al., 2014). As arsenic belongs to nonessential group of elements, so its exposure for long time results in lungs, skin and bladder cancer (Modal and Suzuki, 2002; Morales et al., 2000). Sources of lead are polluted water, soil and air. Water becomes polluted with lead when it passes through lead solder, lead containing pipes and brass fixtures (Tareen et al.,

*Author for correspondence:

E-mail: rana.khizarhayat@gmail.com
2014). Lead (Pb) effects on normal functions of circulatory system, kidneys, reproductive and nervous system (Singh et al., 2010; Duruibe et al., 2007; Jarup, 2003). The sources of chromium (Cr) [i.e. Cr(III) and $\mathrm{Cr}(\mathrm{VI})]$ and its compounds in air, soil and water are natural as well as anthropogenic. They come in water from sewage and industrial effluents of leather and steel industries. Their compounds also come from procedures like electroplating and pigmentation (Venkateswaran et al., 2007; Nath et al., 2005). It has been shown from several studies that exposure to chromium (VI) compounds for longer time may result in lung cancer, ulcers, liver and kidney damage, convulsions, upset stomach and even death (Barceloux and Barceloux, 1999).

Arsenic poisoning is observed in Argentina, China, Chile, Canada, Mexico, Greece, Japan, Mongolia, South Africa, New Zealand, Taiwan, Philippines, Thiland and USSR states. Thus, contamination of water due to arsenic is rising as a world problem (Tahir et al., 2012). Arsenic and other toxic metals are also measured in various regions of Pakistan, recently. This study was carried out to assess the concentrations of $\mathrm{As}, \mathrm{Pb}$ and $\mathrm{Cr}$ in drinking water of various regions of Sahiwal district because there was no significant data available on water quality in that area (Fig. 1). 


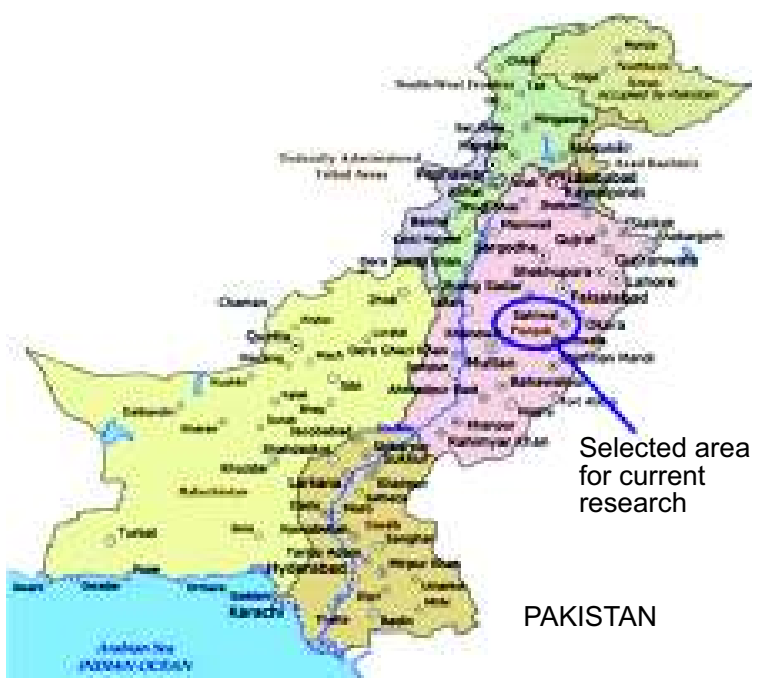

Fig. 1. Study area.

\section{Materials and Methods}

Reagents and standards for arsenic (III). Standard arsenic solution. Stock solution of arsenic was prepared by adding $173.33 \mathrm{mg}$ sodium arsenite (Wako, analytical grade) in $100 \mathrm{~mL}$ deionized water from which required standards were prepared. $1 \% \mathrm{w} / \mathrm{v} \mathrm{KIO}_{3}$ (analytical grade, Merck) aqueous solution was prepared. 0.5 $\mathrm{M}$ hydrochloric acid ( $\mathrm{HCl}$, analytical grade, Merck) and $2 \mathrm{M}$ sodium hydroxide $(\mathrm{NaOH}$, Merck, analytical grade) were prepared. $250 \mathrm{mg}$ Leucocrystal violet (LCV, analytical grade, Sigma), $3 \mathrm{~mL}$ phosphoric acid (85\%, Merck, analytical grade) and $200 \mathrm{~mL}$ deionized water were added in $1 \mathrm{~L}$ flask for preparation of LCV solution. Shook them gently to dissolve dye and diluted upto the mark. The colour of solution was light yellow.

Reagents and standards for chromium (VI). Diphenylcarbazide-acetone solution. Diphenylcarbazide (Merck) solution ( $0.25 \%$ ) in 50\% acetone was prepared. Sulphuric acid $\left(\mathrm{H}_{2} \mathrm{SO}_{4}\right.$, Merck, analytical grade) $3 \mathrm{M}$ and $0.0002 \mathrm{M}$ standard stock solution of potassium dichromate $\left(\mathrm{K}_{2} \mathrm{Cr}_{2} \mathrm{O}_{7}\right.$, Sigma, analytical grade) were prepared. Required standards of $\mathrm{K}_{2} \mathrm{Cr}_{2} \mathrm{O}_{7}$ were prepared from this stock solution.

Chemicals used in ICP-MS. Reagent water. High purity Milli-Q water was used for blank and standard solutions preparation, which was free of interferences obtained from Millipore deionizer system. $<2 \% \mathrm{v} / \mathrm{v}$ nitric acid $\left(\mathrm{HNO}_{3}\right.$, Fluka, analytical grade) and $1 \% \mathrm{v} / \mathrm{v}$ highly pure $\mathrm{HCl}$ (Merck) were used for the preparation of blank and standard solutions. High purity $(>99.99 \%$ purity) standard solutions of $100 \mathrm{mg} / \mathrm{L}$ were purchased from Analytika, which were of ICP/MS-grade used for calibrating curves and standards preparation.

Instruments. Spectrophotometer UV-1900 (BMS) was used for As(III) and $\mathrm{Cr}$ (VI) evaluation while ICP-MS (Agilent 7700x) was used for the evaluation of $\mathrm{As}_{\text {total }}$, $\mathrm{Cr}_{\text {total }}$ and $\mathrm{Pb}$ with an autosampler of Agilent ASX-500.

Sampling. Water samples were collected according to the guidelines and standard protocol of collecting samples of $22^{\text {nd }}$ edition of American Public Health Association (APHA). Sample's collection was carried out in polyethylene bottles which were washed by soaking for overnight with $10 \% \mathrm{HNO}_{3}$ (Merck, Suprapur grade), rinsed with deionized water and dried in an area free of metals (Fancesconi and Kuehnelt, 2004).

Sample sources, preservation and storage. Water samples were taken from four sources, i.e., tap water, hand pump, tubewell and filter plant. All samples were obtained from the depth of 60 to 90 feet below the surface. 40 precleaned bottles were labeled with permanent marker for 20 sampling points. The details of sampling points are given in Table 1. Two samples were taken from each sampling point. To avoid from contamination, the bottles were rinsed with water sample of particular point, three times. To measure the analytes exactly and accurately, $0.5 \mathrm{~mL} \mathrm{HNO}_{3}$ (Suprapur grade) was added as preservative. The samples were stored at $4{ }^{\circ} \mathrm{C}$ in refrigerator before analysis. The samples were divided into two portions, each portion had 20 samples. One portion was analysed by ICP-MS at PCSIR Research Laboratory of Pakistan. The other portion was analysed for the evaluation of $\mathrm{As}(\mathrm{III})$ and $\mathrm{Cr}(\mathrm{VI})$ quantitatively on spectrophotometer (UV-1900, BMS).

Methodology. A number of methods are used for the As evaluation, i.e., cathodic stripping voltammetry (CSV) (Ferreira and Barros, 2002), spectrophotometry (Dasgupta, 2002) hydride generation-atomic absorption spectrometry (Bundaleska et al., 2005), potentiometry (Gupta and Agarwal, 2005) and inductively coupled plasma-mass spectrometry (ICP-MS) (Shraim et al., 2013).

To determine arsenic quantitatively, detection limit of $\leq 1 \mathrm{ppb}$ is desired which can only be achieved by using ICP. So, for precise and accurate calculation of arsenic, ICP-MS was used. As arsenic (III) is more toxic than arsenic (V) (Maria et al., 2013), so its calculation is 
Table 1. Details of sampling points

\begin{tabular}{ll}
\hline \hline Location & Detail \\
\hline SLF1 & Filter water of Tariq Bin Ziad Colony (TBZC) \\
SLH1 & Hand pump of TBZC \\
SLT1(I) & Tap water of Government Commerce College for \\
& Females, TBZC \\
SLT1(II) & Tap water of Faridia park, TBZC \\
SLF2 & Filter water of Bhutto Nagar \\
SLH2 & Hand pump of Bhutto Nagar \\
SLH3 & Hand pump of Ghalla Mandi \\
SLT3(I) & Tap water of Ghalla Mandi \\
SLT3(II) & Tap water of Government Mehmoodia \\
& High School, Ghalla Mandi \\
SLF4 & Filter water of New Abadi \\
SLTW4 & Tubewell water of New Abadi \\
SLT5 & Tap water of 90/9-L \\
SLTW5 & Tubewell water of 90/9-L \\
SLT6 & Tap water of Sharif Colony \\
SLTW6 & Tubewell water of Sharif Colony \\
SLF7 & Filter water of Tehsil chock \\
SLT8(I) & Tap water of Government High School \\
& Urban area, Bilal Colony \\
SLT8(II) & Tap water of AIOU Sahiwal campus, Bilal Colony \\
SLT9 & Tap water of Government High School Nangal-2, \\
& mohalla Farid Gonj \\
SLT10 & Tap water of Farid Town \\
\hline \hline
\end{tabular}

also necessary. Since, ICP gives only the quantity of $\mathrm{As}_{\text {total }}[$ i.e. As(III) \& $\mathrm{As}(\mathrm{V})]$, spectrophotometric methods are mostly used to quantify the level of As(III) because of their ease of availability in every lab and ease of operation. Since in all the spectrophotometric methods either toxic reagents are used, or extraction of toxic gas arsine $\left(\mathrm{AsH}_{3}\right)$ is required, so a non extracted procedure with leuco crystal violet for As(III) quantification was used. This method encounters less interference of other ions than other methods. It is more sensitive and stable colour formation of oxidized dye occurrence (Agrawal et al., 1999).

Similarly, evaluation of $\mathrm{Cr}_{\text {total }}$ [Cr(III) and $\left.\mathrm{Cr}(\mathrm{VI})\right]$ was carried out by using ICP-MS (Shraim et al., 2013). Out of a number of procedures for $\mathrm{Cr}(\mathrm{VI})$ determination, spectrophotometric methods are preferred because of easiness to approach and friendly to climate (Khan et al., 2013). In the present work the level of Cr(VI) was determined colorimetrically with 1,5-diphenylcarbazide reagent because all the other reagents used in this method are easily available in every lab and the complexing agent is also cheaper. There was no evolution of toxic gas during the experiment and the procedure completed within very short time, are the additional merits of this method (Mendham et al., 1998). Since, lead is present in very small amount in water so its evaluation was also done by most accurate and precise method ICP-MS (Shraim et al., 2013). Concentration of these heavy metals in drinking water of Sahiwal is showed Table 2.

For arsenic (III). A small amount of sample having 0.004 to $0.04 \mathrm{ppm}(4-40 \mathrm{ppb})$ arsenic was taken in a calibrated tube of $25 \mathrm{~mL} .2 \mathrm{~mL} \mathrm{KIO}_{3}$ was added followed with the addition of $1 \mathrm{~mL}$ solution of $\mathrm{HCl}$. All the reagents were shaken thoroughly then added $1 \mathrm{~mL}$ solution of LCV followed by 4-5 drops of $2 \mathrm{M}$ solution of $\mathrm{NaOH}$. The solution was kept for $5 \mathrm{~min}$ in a thermostat at $40{ }^{\circ} \mathrm{C}$. The solution was then diluted with deionized water upto $25 \mathrm{~mL}$ and the absorbance was measured against a reagent blank at $592 \mathrm{~nm}$ (Agrawal et al., 1999).

For chromium (VI). Method used for $\mathrm{Cr}(\mathrm{VI})$ evaluation is reported in Vogel's Textbook (Mendham et al., 1998) is as follows:

$15 \mathrm{~mL}$ of sample was taken in $25 \mathrm{~mL}$ calibrated tube and sufficient $3 \mathrm{M} \mathrm{H}_{2} \mathrm{SO}_{4}$ was added to make the concentration $0.1 \mathrm{M}$ followed by $1 \mathrm{~mL}$ of reagent

Table 2. Concentration of heavy metals in drinking water of Sahiwal district

\begin{tabular}{|c|c|c|c|c|c|}
\hline Locations & $\begin{array}{l}\text { As(III) } \\
(\mu \mathrm{g} / \mathrm{L})\end{array}$ & $\begin{array}{l}\text { As } s_{\text {total }} \\
(\mu \mathrm{g} / \mathrm{L})\end{array}$ & $\begin{array}{l}\mathrm{Cr}(\mathrm{VI}) \\
(\mathrm{mg} / \mathrm{L})\end{array}$ & $\begin{array}{l}\mathrm{Cr}_{\text {total }} \\
(\mathrm{mg} / \mathrm{L})\end{array}$ & $\begin{array}{l}\mathrm{Pb} \\
(\mu \mathrm{g} / \mathrm{L})\end{array}$ \\
\hline SLF1 & 4.92 & 5.60 & 5.59 & 5.62 & 6.81 \\
\hline SLH1 & 8.93 & 9.33 & 4.70 & 4.72 & 6.02 \\
\hline SLT1 (I) & 6.88 & 7.14 & 4.77 & 4.79 & 6.14 \\
\hline SLT1 (II) & 8.06 & 8.89 & 6.37 & 6.40 & 3.97 \\
\hline SLF2 & 17.98 & 18.43 & 6.11 & 6.13 & 5.04 \\
\hline SLH2 & 21.04 & 21.64 & 5.39 & 5.42 & 7.18 \\
\hline SLH3 & 23.97 & 25.03 & 5.68 & 5.70 & 9.23 \\
\hline SLT3 (I) & 20.02 & 20.39 & 5.23 & 5.25 & 12.43 \\
\hline SLT3 (II) & 19.17 & 20.70 & 5.13 & 5.13 & 20.69 \\
\hline SLF4 & 14.31 & 15.10 & 5.99 & 6.01 & 3.68 \\
\hline SLTW4 & 14.95 & 15.08 & 5.33 & 5.34 & 2.31 \\
\hline SLT5 & 9.12 & 9.55 & 5.61 & 5.62 & 4.78 \\
\hline SLTW5 & 7.85 & 8.63 & 5.33 & 5.34 & 3.98 \\
\hline SLT6 & 11.78 & 12.09 & 5.92 & 5.97 & 12.27 \\
\hline SLTW6 & 9.23 & 9.97 & 5.85 & 5.89 & 9.91 \\
\hline SLF7 & 5.64 & 5.78 & 5.81 & 5.83 & 4.39 \\
\hline SLT8 (I) & nd & nd & 6.23 & 6.24 & 7.83 \\
\hline SLT8 (II) & nd & nd & 5.54 & 5.57 & 7.32 \\
\hline SLT9 & nd & nd & 4.63 & 4.65 & 4.73 \\
\hline SLT10 & nd & nd & 5.53 & 5.55 & 2.03 \\
\hline
\end{tabular}


diphenylcarbazide. Deionized water was added upto the mark of $25 \mathrm{~mL}$ and the absorbance was measured at $540 \mathrm{~nm}$. The absorbance of $0.0002 \mathrm{M} \mathrm{K}_{2} \mathrm{Cr}_{2} \mathrm{O}_{7}$ (standard stock solution) was measured at $540 \mathrm{~nm}$ having known quantity $(2.08 \mathrm{mg} / \mathrm{L})$ of $\mathrm{Cr}(\mathrm{VI})$. By comparing the absorbance of test solution with standard stock solution the quantity of $\mathrm{Cr}(\mathrm{VI})$ in test solution was measured.

For ICP-MS. EPA method 6020A ICP/MS (2007) was used for As and other toxic metals evaluation.

\section{Results and Discussion}

The values of $\mathrm{As}$ (III) and arsenic $_{\text {total, }}$ are given in (Fig. 2-3) and its ranges in tap, tube well, filter plant and hand pump water are given in Table 3. Arsenic was detected at ppb level, so its values are given in $\mu \mathrm{g} / \mathrm{L}$. It is signified from the Fig. 2-3 that the locations SLT3(I), SLT3(II), SLF2, SLH2 and SLH3 have higher values of As(III) and Astotal but still they are within the permissible limits of Pakistan Environmental Protection Agency (Pak EPA, 2010). Since, 8 locations had arsenic levels greater than $10 \mu \mathrm{g} / \mathrm{L}$, so $40 \%$ drinking water of the studied area was unfit and $60 \%$ was fit according

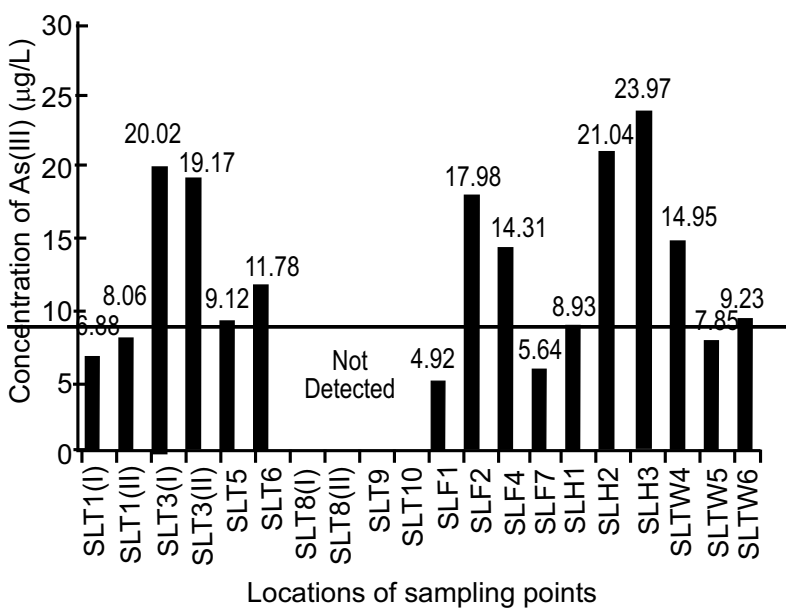

Fig. 2. Comparison of As(III) concentrations. to World Health Organization (WHO) limit. All the water samples had arsenic levels lower than $50 \mu \mathrm{g} / \mathrm{L}$ set by Pak EPA, so the water of all the locations was $100 \%$ suitable for drinking according to Pak-EPA Standards. Furthermore, the mean level of arsenic $10.668 \mu \mathrm{g} / \mathrm{L}$ was 4.687 times lower than Pak-EPA Standard value and 1.0668 times higher than WHO limit of $10 \mu \mathrm{g} / \mathrm{L}$ also verified that the water of Sahiwal district was fit for drinking purpose related to arsenic. The range of $\mathrm{As}_{\text {total }}(\mathrm{nd}-25.03 \mu \mathrm{g} / \mathrm{L}$ ) was 0-1.044 times higher than the range of As(III) (nd-23.97 $\mu \mathrm{g} / \mathrm{L}$ ) indicating that most of the arsenic was present in more toxic $\mathrm{As}(\mathrm{III})$ form.

Figures 4-5 illustrate the levels of chromium (VI) and chromium $_{\text {total }}$ in all types of water samples. These figures show that the concentrations of chromium are very high as compared to Pak EPA, United States Environmental Protection Agency (USEPA, 2011) and World Health Organization (WHO, 2008) recommended values, which is also explained by Table 4-6. The mean level of $\mathrm{Cr}$ was $5.559 \mathrm{mg} / \mathrm{L}$ which was 111.18 times higher than WHO and local standard of $0.05 \mathrm{mg} / \mathrm{L}$. It was also clear from the ranges of $\mathrm{Cr}_{\text {total }}(4.65-6.40 \mathrm{mg} / \mathrm{L})$ and $\mathrm{Cr}(\mathrm{VI})$

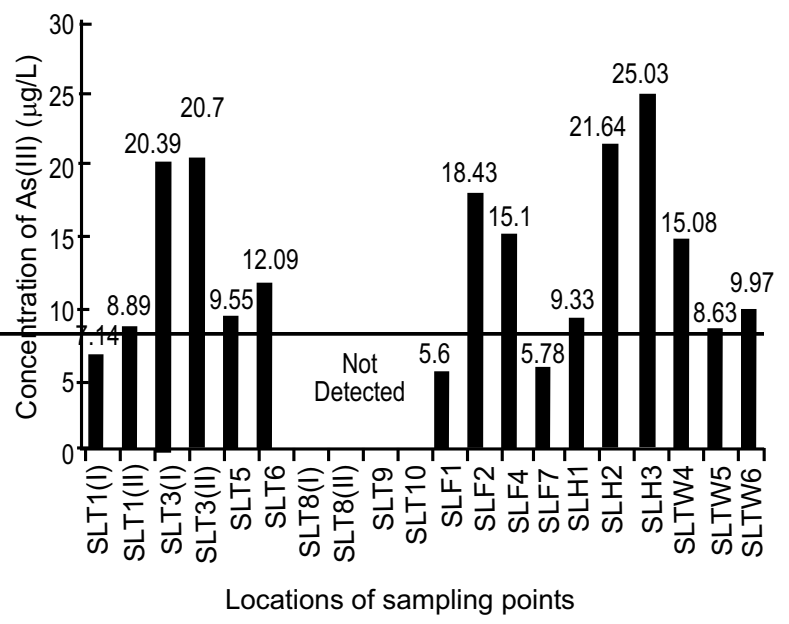

Fig. 3. Comparison of $\mathrm{As}_{\text {total }}$ concentrations.

Table 3. Ranges of levels $\mathrm{As}(\mathrm{III}), \mathrm{As}_{\text {total }}, \mathrm{Cr}(\mathrm{VI}), \mathrm{Cr}_{\text {total }}$ and $\mathrm{Pb}$ in tap, filter plant, hand pump and tube well water

\begin{tabular}{lllll}
\hline \hline Metal & Tap water & Filter plant water & Hand pump water & Tube well water \\
\hline $\mathrm{As}(\mathrm{III})(\mu \mathrm{g} / \mathrm{L})$ & nd-20.02 & $4.92-17.98$ & $8.93-23.97$ & $7.85-14.95$ \\
$\mathrm{As}$ total $(\mu \mathrm{g} / \mathrm{L})$ & nd-20.70 & $5.60-18.43$ & $9.33-25.03$ & $8.63-15.10$ \\
$\mathrm{Cr} r_{\text {total }}(\mathrm{mg} / \mathrm{L})$ & $4.65-6.40$ & $5.62-6.13$ & $4.72-5.70$ & $5.34-5.89$ \\
$\mathrm{Cr}(\mathrm{VI})(\mathrm{mg} / \mathrm{L})$ & $4.63-6.37$ & $5.59-6.11$ & $4.70-5.68$ & $5.33-5.85$ \\
$\mathrm{~Pb}(\mu \mathrm{g} / \mathrm{L})$ & $2.03-20.69$ & $3.68-6.81$ & $6.02-9.23$ & $2.31-9.91$ \\
\hline \hline
\end{tabular}


(4.63-6.37 mg/L) that $\mathrm{Cr}_{\text {total }}$ was 1.0043-1.0047 times greater than $\mathrm{Cr}(\mathrm{VI})$ exhibited that $\mathrm{Cr}(\mathrm{VI})$ was the major pollutant in drinking water of that region.

Figure 6 shows the concentrations of lead in different types of water samples. The maximum concentrations of lead are found at the sampling points SLT3(I), SLT3(II) and SLT6 but they are lower than the guided values of Pak EPA. Lead was within the range of 2.03$20.69 \mu \mathrm{g} / \mathrm{L}$. The mean value of $\mathrm{Pb}$ was $7.037 \mu \mathrm{g} / \mathrm{L}$ which was 1.421 times smaller than WHO limit of 10 $\mu \mathrm{g} / \mathrm{L}$ and 7.1053 times lower than Pak-EPA Standard value of $50 \mu \mathrm{g} / \mathrm{L}$. It was also observed that $3(15 \%)$ samples had crossed the WHO limit of $10 \mathrm{ppb}$ and no sample had crossed the Pak EPA limit of $50 \mathrm{ppb}$, so all the samples were suitable according to national standard for $\mathrm{Pb}$.

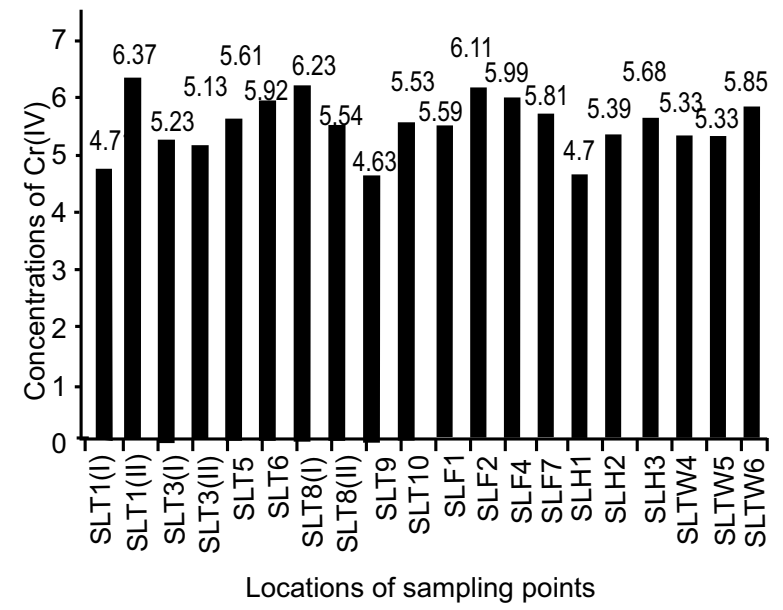

Fig. 4. Comparison of $\mathrm{Cr}(\mathrm{VI})$ concentrations.

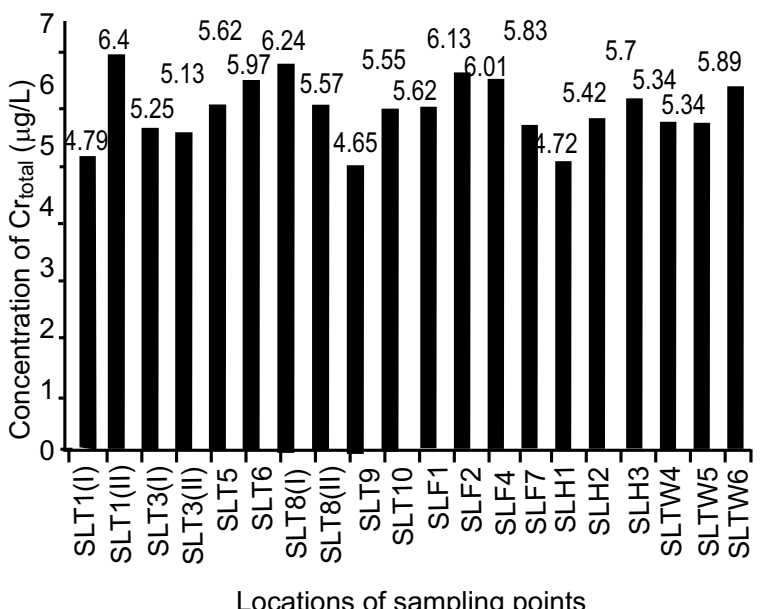

Fig. 5. Comparison of $\mathrm{Cr}_{\text {total }}$ concentrations.
Table 4. The mean levels of arsenic $\mathrm{c}_{\text {total }}$, chromium total and lead in drinking water of Sahiwal district and its comparison with Pak EPA, EPA and WHO

\begin{tabular}{llllll}
\hline \hline Metals & Unit & Mean level & Pak EPA & USEPA & WHO \\
\hline $\mathrm{As}$ & $\mu \mathrm{g} / \mathrm{L}$ & 10.668 & $\leq 50$ & 50 & 10 \\
$\mathrm{Cr}$ & $\mathrm{mg} / \mathrm{L}$ & 5.559 & $\leq 0.05$ & 0.10 & 0.05 \\
$\mathrm{~Pb}$ & $\mu \mathrm{g} / \mathrm{L}$ & 7.037 & $\leq 50$ & 15 & 10 \\
\hline \hline
\end{tabular}

Table 5. Number of locations with the level of toxic metals $>10 \mu \mathrm{g} / \mathrm{L}$ out of total 20 locations

\begin{tabular}{llll}
\hline \hline Metal & $\begin{array}{l}\text { No. of } \\
\text { locations }\end{array}$ & $\begin{array}{l}\text { \% of locations greater } \\
\text { than } 10 \mu \mathrm{g} / \mathrm{L}\end{array}$ & $\begin{array}{l}\text { Locations crossing } \\
\text { WHO limits }\end{array}$ \\
\hline Astotal $_{\text {tota }}$ & 8 & $40 \%$ & 8 \\
$\mathrm{Cr}_{\text {total }}$ & 20 & $100 \%$ & 20 \\
$\mathrm{~Pb}$ & 3 & $15 \%$ & 3 \\
\hline \hline
\end{tabular}

Table 6. Number of locations with the levels of toxic metals $>50 \mu \mathrm{g} / \mathrm{L}$ out of total 20 locations

\begin{tabular}{llll}
\hline \hline Metal & $\begin{array}{l}\text { No. of } \\
\text { locations }\end{array}$ & $\begin{array}{l}\text { \% of locations greater } \\
\text { than } 50 \mu \mathrm{g} / \mathrm{L}\end{array}$ & $\begin{array}{l}\text { Locations crossing } \\
\text { WHO limits }\end{array}$ \\
\hline $\mathrm{As}_{\text {total }}$ & 0 & $0 \%$ & 0 \\
$\mathrm{Cr}_{\text {total }}$ & 20 & $100 \%$ & 20 \\
$\mathrm{~Pb}$ & 0 & $0 \%$ & 0 \\
\hline \hline
\end{tabular}

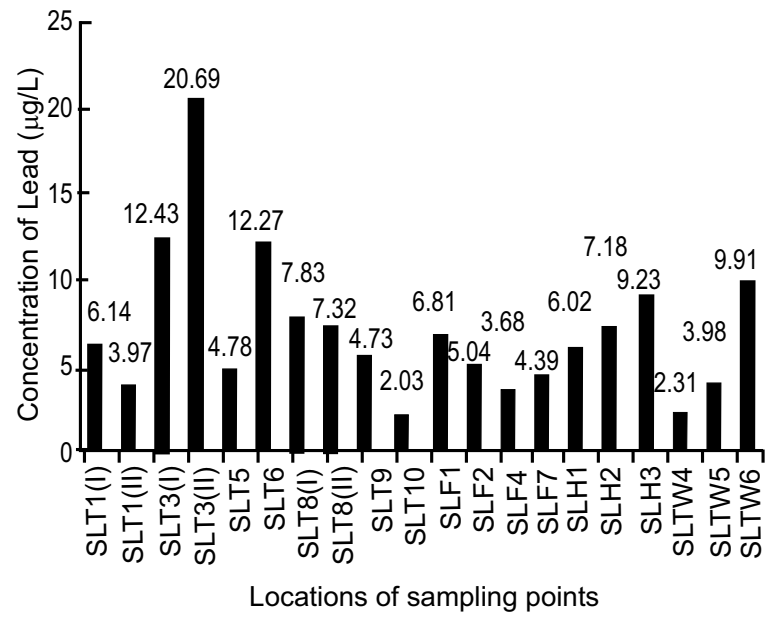

Fig. 6. Comparison of $\mathrm{Pb}$ concentrations.

There are few leather factories in district Sahiwal which discharge their effluents containing chromium and arsenic in underground water resources due to which the levels of arsenic and especially chromium (VI) were 
very high in drinking water. The other sources of arsenic in water were the use of arsenic containing pesticides and manufacturing of preservatives of wood. Chromium was present in all the samples crossing the local and international standards of WHO and USEPA. Hence, a constant monitoring of it is required in this area. Since $\mathrm{Cr}(\mathrm{VI})$ is toxic and its toxicity can be reduced by converting it into less toxic $\mathrm{Cr}(\mathrm{III})$ which is possible by reduction of $\mathrm{Cr}(\mathrm{VI})$. Therefore, reduction of $\mathrm{Cr}(\mathrm{VI})$ in drinking water of Sahiwal should be carried out by the government and international cooperation like World Bank, WHO, UNDP and UNICEF. Sources of Pb in drinking water could be anthropogenic as well as natural. $\mathrm{Pb}$ from household plumbing system e.g. fittings, solder, pipes dissolves in drinking water and its dissolution depends on various factors like $\mathrm{pH}$, chloride, $\mathrm{DO}$, water standing time and hardness. A comparative study of all studied toxic metals concentrations is depicted in (Fig. 7).

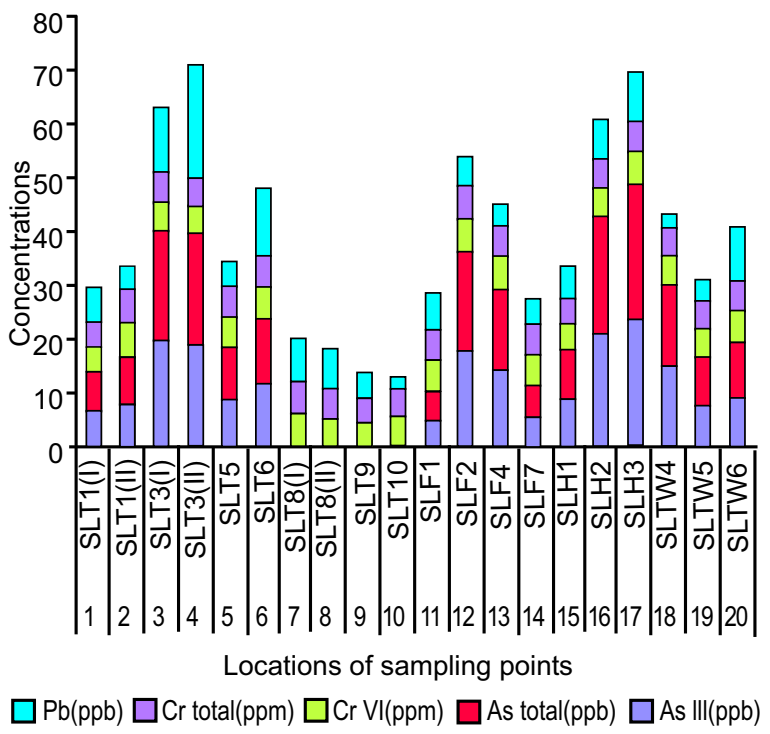

Fig. 7. Comparison of concentrations of all the studied toxic metals.

\section{Conclusion and Recommendations}

It is concluded that the concentrations of arsenic and lead were satisfactory in the area of Sahiwal and were lower than the Pak-EPA Standard values with the exception of chromium. Chromium level was greater than Pak EPA and international standards in all the locations hence quick action is required to alleviate the hazardous effects of this metals. To prevent the increased concentration of contaminant in future, it is necessary to monitor the drinking water quality and to follow the following recommendations.

1. The locations having higher level of arsenic, lead and chromium should be confirmed by further assessment and good quality water should be managed alternatively.

2. To overcome the hazardous effects of arsenic and other toxic metals in water, people should be informed immediately by communication and mass media.

3. The procedures for the removal of arsenic and other toxic metals should be developed and used at community and domestic level.

4. WHO, World Bank, UNDP and UNICEF are recommended to support financially for the implementation of above points.

\section{Acknowledgement}

The author would like to acknowledge the support of Professor Dr. Shahid Tufail, Department of Chemistry, MUL, Pakistan and Associate Professor Khalid Mehmood Rana, Government Post Graduate Islamia College, Gujranwala, Pakistan, for providing academic and laboratory facilities for drinking water samples.

\section{References}

Agrawal, O., Sunita, G., Gupta, V.K. 1999. A sensitive colorimetric method for the determination of arsenic in environmental and biological samples. Journal of Chinese Chemical Society, 46: 641-645.

Barceloux, D. G. 1999. Chromium, Clinical Toxicology. Journal of Toxicology, 37: 173-194.

Bundaleska, J.M., Stafilov, T., Arpadjan, S. 2005. Direct analysis of natural waters for arsenic species by hydride generation atomic absorption spectrometry. International Journal of Environmental Analytical Chemistry, 85: 199-207.

Dasgupta, P.K., Huang, H., Zhang, G., Cobb, G.P. 2002. Photometric measurement of trace As(III) and $\mathrm{As}(\mathrm{V})$ in drinking water. Talanta, 58: 153-164.

Duruibe, J.O., Ogwuegbu, M.O.C., Egwurugwu, J.N. 2007. Heavy metal pollution and human biotoxic effects. International Journal of Physical Sciences, 2: 112-118.

Fancesconi, K.A., Kuehnelt, D. 2004. Determination of arsenic species: A critical review of methods and applications, 2000-2003. The Analyst, 129: 373-395. 
Ferreira, M.A., Barros, A.A. 2002. Determination of $\mathrm{As}(\mathrm{III})$ and arsenic (V) in natural waters by cathodic stripping voltammetry at a hanging mercury drop electrode. Analytical Chimica Acta, 459: 151-159.

Gupta, V.K., Agarwal, S. 2005. PVC based 5, 10, 15, 20-tetrakis (4-methoxyphenyl) porphyrinatocobalt (II) membrane potentiometric for arsenite. Talanta, 65: $730-734$.

Ikhlaq, A., Kazmi, M., Hayder, S., Mian, H.R., Rustam, M., Sulheri, A.W., Saeed, A. 2014. Evaluation of drinking water quality parameters in the areas of East-Lahore Pakistan: A case study. Journal of Faculty of Engineering and Technology (JFET), 21: 1-21.

Jarup, L. 2003. Hazards of heavy metal contamination. British Medical Bulletin, 68: 167-182.

Johnson, D.G., Hallberg, K.B. 2005. Acid mine drainage remediation options: a review. Science Total Environment, 338: 3-14.

Khan, H., Talpur, F.N., Shah, A., Balouch, A. 2013. Ultra trace spectrophotometric determination of chromium in presence of cationic micellar solution. Sindh University Research Journal (Science Series), 45: 141-148.

Maria, G.C., Balalau, D., Mihaela, I., Nicoleta, P.C., Miriana, G. 2013. Quantitative determination of arsenic in bottled drinking water using atomic absorption spectrometry. Acta Medica Marisiensis, 59: 246-249.

Mendham, J., Denney, R.C., Barnes, J.D., Thomas, M., Sivasankar, B. 1998. Vogel's Textbook of Quantitative Chemical Analysis, $6^{\text {th }}$ edition, 651 pp., UK.

Modal, B.K., Suzuki, K.T. 2002. Arsenic round the world: (A review). Talanta, 58: 201-235.

Morales, K.H., Ryan, L., Kuo, T.L., Wu, M.M., Chen, C.J. 2000. Risk of internal cancers from arsenic in drinking water. Environmental Health Perspectives, 108: $655-661$.
Nath, K., Saini, S., Sharma, Y.K. 2005. Chromium in tannery industry effluent and its effect on plant metabolism and growth. Journal of Environmental Biology, 26: 197-204.

Pak-EPA, 2010. National Standards for Drinking Water Quality. Pakistan Environmental Protection Agency. The Gazette of Pakistan, Ministry of Environment (G.O.P.M.E) Islamabad, Pakistan.

Shraim, A.M., Alsuhaimi, A.O., Muzaini, K.O., Kurdi, K., Ameen, H.A. 2013. Quality assessment of groundwater of Almadinah Almunawarah city. Global NEST Journal, 15: 374-383.

Singh, A., Sharma, R.K., Agrawal, M., Marshall F.M. 2010. Risk assessment of heavy metal toxicity through contaminated vegetables from waste water irrigated area of Varanasi, India. Tropical Ecology, 51: 375-387.

Tahir, M.A., Rasheed, H., Malana, A. 2012. Method development for arsenic analysis by modification in spectrophotometric technique. Drinking Water Engineering and Science, 5: 1-8.

Tareen, A.K., Sultan, I.N., Parakulsuksatid, P., Shafi, M., Khan, A., Khan, M.W., Husain, S. 2014. Detection of heavy metals $(\mathrm{Pb}, \mathrm{Sb}, \mathrm{Al}, \mathrm{As})$ through atomic absorption spectroscopy from drinking water of District Pishin, Balochistan, Pakistan. International Journal of Current Microbiology and Applied Sciences, 3: 299-308.

USEPA, 2011. Drinking water parameters. Safe Drinking Water Act (SDWA), EPA, USA.

Venkateswaran, P., Vellaichamy, S., Palanivelu, K. 2007. Speciation of heavy metals in electroplating industry sludge and wastewater residue using inductively coupled plasma. International Journal of Environmental Science and Technology, 4: 497-504.

WHO, 2008. Guidelines for Drinking-water Quality, $3^{\text {rd }}$ edition, World Health Organization, Geneva, Switzerland. 